Journal of Atmospheric and Solar-Terrestrial Physics

Volume 121, Part B, December 2014, Pages 221-228

doi:10.1016/j.jastp.2014.03.001

\title{
Whistlers Detected and Analyzed by Automatic Whistler Detector (AWD) at Low Latitude Indian Stations
}

Abhay K. Singh ${ }^{* a}$, S. B. Singh ${ }^{\mathrm{a}}$, Rajesh Singh ${ }^{\mathrm{b}}$, Sneha A. Gokani ${ }^{\mathrm{b}}$, Ashok K. Singh ${ }^{\mathrm{c}}$, Devendraa Siingh $^{\mathrm{d}}$ and János Lichtenberger ${ }^{\mathrm{ef}}$

${ }^{a}$ Atmospheric Research Lab., Department of Physics, Banaras Hindu University, Varanasi 221005, India.

${ }^{b}$ KSK Geomagnetic Research Laboratory, Indian Institute of Geomagnetism, Chamanganj, Allahabad, India.

${ }^{\mathrm{c}}$ Physics Department, Lucknow University, Lucknow 226 007, India.

${ }^{\mathrm{d} I n d i a n}$ Institute of Tropical Meteorology, Pune-411 008, India.

'Space Research Group, Department of Geophysics and Space Sciences, Eötvös University, Budapest, Hungary.

${ }^{\mathrm{f}}$ Geodetic and Geophysical Institute, Research Center for Astronomy and Earth Sciences, Hungarian Academy of Sciences, Sopron, Hungary.

\section{"Corresponding Author}

Prof. Abhay Kumar Singh 
Atmospheric Research Lab., Department of Physics,

Banaras Hindu University, Varanasi-221 005, India.

E-mail: abhay_s@rediffmail.com

Phone No:+919415303722

Fax No: +91-0542-2368390

\section{Abstract}

Recently, at three Indian low latitude stations: Varanasi (geomag. lat. $14^{0} 55^{\prime} \mathrm{N}$, geomag. long. $153^{0} 54^{\prime} \mathrm{E}, \mathrm{L}: 1.078$ ), Allahabad (geomag. lat.16.05ํN; geomag. long. $155.34^{0} \mathrm{E}, \mathrm{L}: 1.081$ ) and Lucknow (geomag. lat.17.6 $\mathrm{N}$, geomag. long. 154.5 E, L: 1.104) an Automatic Whistler Detector (AWD) has been installed in December, 2010 for detection and analysis of whistlers. This instrument automatically detects and collects statistical whistlers data for the investigation of whistlers generation and propagation. Large numbers of whistlers have been recorded at Varanasi and Allahabad during the year 2011 which is analyzed in the present study. Different types of whistlers have been recorded at Varanasi and Allahabad. The correlation between recorded whistlers and causative lightning strikes were analyzed using data provided by WorldWide Lightning Location Network (WWLLN). We observed that for both the stations more than $50 \%$ of causative sferics of whistlers were observed to match closely with the times of WWLLN detected lightning strikes within the propagation times of causative tweeks. All of these lightning strikes originated from the region within 500-600 km radius circle from the conjugate point of Varanasi and Allahabad which supports the ducted propagation at low latitude stations. The dispersion of the observed whistlers varies between 8 and $18 \mathrm{sec}^{1 / 2}$, which shows that the observed whistlers have propagated in ducted mode and whole propagation path of whistlers lies in the ionosphere. The ionospheric columnar electron contents of these observed whistlers vary between 13.21 TECU and 56.57 TECU. The ionospheric parameters derived from whistler data at Varanasi compare well with the other measurements made by other techniques. 
Keywords: Very Low Frequency Waves, Whistlers, Lightning discharges, plasmaspheric parameters, Magnetospheric Physics.

\section{Introduction:}

Very Low Frequency (VLF, 3-30 kHz) electromagnetic waves are a powerful tool for remote sensing of processes in the ionosphere and magnetosphere (Helliwell, 1965). VLF waves, which are generated by lightning return stroke currents (sferics, whistlers) travel between hemispheres along ionization ducts before entering the Earth-ionosphere wave-guide (Storey, 1953). Continuous monitoring and analysis of these waves (such as: radio atmospheric, tweeks, whistlers, VLF emissions) yield information about the height of the waveguide, equatorial electron density profiles (Tarcsai et al., 1988), electron/ion temperature (Sazhin et al., 1990), convective electric fields in the magnetosphere (Carpenter et al., 1972), duct width, duct lifetime (Singh et al., 1998), irregularities in the electron density (in the magnetosphere as well as lower ionosphere), lightning induced electron precipitation (LEP) (Inan et al., 2010), etc. (Siingh et al., 2008 and references therein). Whistlers explain wave propagation and related properties of VLF waves having right hand polarization and wave frequency smaller than the electron gyrofrequency and electron plasma frequency (Helliwell, 1965, Sazhin et al., 1992). These waves have been received both on the Earth's surface (Walker, 1976; Collier et al., 2006) as well as onboard satellites (Chum et al., 2006).

The whistler waves can propagate through the magnetospheric plasma in a ducted mode (Walker, 1976), a non-ducted mode (Smith and Angermi, 1968) and a prolongitudinal mode (Morgan, 1980). When the wave frequency is lower than the lower hybrid resonance frequency and the wave normal angle is relatively small (but not small enough to be trapped in ducts) the 
waves propagate in the prolongitudinal mode (PL) and such whistlers can be received on low altitude satellites known as PL whistlers (Morgan, 1980). Waves propagating in the non-ducted mode can be received only onboard satellites. It is expected that a lightning discharge may illuminate a large area in the ionosphere through which wave energy may enter the magnetosphere to appear as a whistler wave in the conjugate region (Storey, 1953). When a lightning discharge is composed of multiple flashes and VLF energy propagates in the same duct, the series of whistlers having the same dispersion and separated in time are called "multiflash" whistlers (Helliwell, 1965; Singh et al., 2011). When a lightning discharge illuminates more than one duct simultaneously in the magnetosphere then "multi-path" whistlers are produced (Helliwell, 1965). The dynamic spectra of whistlers are controlled by the path-length, the distribution of electron density and the magnetic field along the path of propagation (Park, 1972).

The analysis of a whistler usually consists of the searching of whistlers in raw VLF data to obtain whistler spectrogram and applying a model using the scaled f-t pairs to calculate plasma and propagation parameters (Helliwell, 1965; Singh et al., 1998). However, it is not practical to manually search continuously recorded VLF data for whistler events as a source of regularly measured plasmaspheric parameters. For this reason an Automatic Whistler Detector (AWD) system (Lichtenberger et al., 2008) has been developed as a step toward producing automatic and near-continuous ground based plasmaspheric measurements. The AWD system was first deployed in Tihany, Hungary $\left(46.89^{\circ} \mathrm{N}, 17.89^{\circ} \mathrm{E} ; \mathrm{L}=1.81\right)$, and identified 252,000 whistler traces over a 2-year period (Collier et al., 2006). Using the AWD system operating in Dunedin, New Zealand, Rodger et al. (2009) reported that Dunedin whistler rates are hundreds of times higher than estimated from the conjugate lightning activity. Chum et al. (2006) have studied the penetration of lightning induced whistler waves through the ionosphere by 
investigating the correspondence between the whistlers observed on the DEMETER and MAGION-5 satellites and the lightning discharges detected by the European lightning detection network EUCLID. They demonstrated that the area in the ionosphere through which the electromagnetic energy induced by a lightning discharge enters the magnetosphere is up to several thousand kilometers wide. This suggested that stations situated within $1000 \mathrm{~km}$ could record the same whistlers. Comparing lightning data and one-hop whistlers obtained from an automatic detection system on the ground, Lichtenberger et al. (2005) and Collier et al. (2006) showed that the primary source of whistlers are cloud-to-cloud lightning and only a minor part of the whistler events are excited by cloud-to-ground discharges. The seasonal occurrence of Tihany-observed whistlers was found to be strongly dependent upon lightning activity in the southern African conjugate region (Collier et al., 2006). Whistler observations peaked in the same month that lightning activity peaked, although the diurnal variation in whistler occurrence peaked in the nighttime and was principally determined by ionospheric absorption rather than the late afternoon-early evening when conjugate lightning activity peaked. Recently, Singh et al. (2012) reported the direct correlation between whistlers observed at a low latitude station, Allahabad $(\mathrm{L}=1.08)$ with their causative lightning discharges located near the conjugate region using the Global Lightning Dataset 360 (GLD360) lightning location network. The World-Wide Lightning Location Network (WWLLN) currently detects the lightning discharges with peak currents larger than $50 \mathrm{kA}$ within the spatial and temporal accuracy of $10 \mathrm{~km}$ and $10 \mu \mathrm{s}$ and has the global detection efficiency of about 10\% (Rodger et al., 2009). Recently, Srivastava et al. (2013) also reported one-to-one relationship between low latitude whistlers and conjugate source lightning discharges using the WWLLN data. 
Initially, whistlers were thought to be a uniquely high- and mid- latitude phenomena. However, ground stations in India, Japan and China showed the occurrence of whistlers at low latitudes (L < 2.3) (Singh and Tantry, 1973; Hayakawa and Tanaka, 1978; Xu et al., 1989). The propagation characteristics of mid- and high- latitude whistlers are well established and hence they have been used extensively there in Earth's plasmaspheric investigations (Helliwell, 1965. 69; Al'pert, 1980; Tarcsai et al., 1988). For whistler wave propagation, the wave normal angle must lie within the transmission cone (Helliwell, 1965), which is much larger in a ducted propagation than in non-ducted one. At low latitudes (geomagnetic latitude $<30^{\circ} ; \mathrm{L}<1.3$ ) the Earth's magnetic field lines have sharp curvature and are embedded in the ionosphere $(<1000$ $\mathrm{km}$ ) where ducts are not supposed to regularly exist, so most of the wave energy does not lie within the transmission cone. Hence, the propagation characteristics of whistler waves at low latitudes remain poorly understood and they have not been used effectively as a diagnostic tool for the low latitude ionosphere. Thus for better understanding the propagation characteristics of low latitude whistlers and their associated lightning source location, the present study have been initiated.

In the present study, we have analyzed the broadband VLF data mainly tweeks and multiple whistlers recorded by Automatic Whistler Detector (AWD) installed at Indian low latitude stations Varanasi and Allahabad during the year 2010. We have computed the origin of these whistlers using the WWLLN data and present arguments on the propagation mechanism of these whistlers. The details about the experimental setup of newly installed Automatic Whistler Detector (AWD) at Indian stations are presented in section 2. The results and discussions of the study are presented in section 3 which includes the occurrence statistics of whistlers recorded at 
Varanasi and Allahabad and the connection between whistlers and causative lightning strikes. Finally, the conclusion of the study is presented in section 4 .

\section{Experimental Setup and data:}

VLF wave fields as a function of time and frequency are being recorded continuously using a crossed loop antenna, pre/main amplifier, VLF receiver and Automatic Whistler Detector (AWD) which is installed simultaneously at three Indian low latitude stations: Varanasi (geomag. lat. $=14^{0} 55^{\prime} \mathrm{N}$, geomag. long. $=153^{0} 54^{\prime} \mathrm{E}, \mathrm{L}=1.078$ ), Allahabad (geomag. lat. $=16.05^{0} \mathrm{~N}$; geomag. long. $155.34^{0} \mathrm{E} ; \mathrm{L}=1.081$ ) and Lucknow (geomag. lat. $=17.6^{0} \mathrm{~N}$, geomag. long. $=$ $\left.154.5^{\circ} \mathrm{E}, \mathrm{L}=1.104\right)$. A detailed description of the AWD system operation and algorithm development can be found in Lichtenberger et al. (2008). A brief description of the AWD system installed at Indian stations is presented here for simplicity to readers. The AWD system consists of the following parts: (i) antenna; (ii) preamplifier; and (iii) AWD software running on a personal computer (PC) with a Linux kernel. Antenna is crossed magnetic loop antennae with areas $\sim 100 \mathrm{~m}^{2}$ orientated geomagnetic north-south and east-west so that the receiver picks up magnetic fields parallel to the ground from any direction. Impedance matched pre-amplifier is placed at the bottom of the antenna for maximum power transfer as well as signal amplification. The amplified VLF signal is then digitized at a sampling rate of $44.1 \mathrm{kHz}$ using a 16 bit soundcard in a PC. The PC time is synchronized with the Pulse Per Second (PPS) signal of a GPS receiver. The PPS timing accuracy is better than $1 \mu \mathrm{s}$, which is smaller than the data sampling period ( $22 \mu \mathrm{s})$ (Lichtenberger et al., 2008).

Data collection is started through init system upon PC boot. There is a user level program called sampler.i386, it communicates with Jackd upon startup and during data logging, it writes 
data on the disk. It opens a file in every hour. Each file is closed when round hour is reached and a new one is immediately opened. The just closed file is then processed by AWD which creates another file that (may) contain whistler trace(s). A file can contain more than one trace if consecutive events found. Whistler files are $4 \mathrm{sec}$ long $(2 \mathrm{sec}$ before and $2 \mathrm{sec}$ after detection are saved) generally, but they are extended in the case of multiple events (the 2-2 sec margins are kept). False detection can occur if specific local noises appear or a close storm generates 'sferics curtain' spoiling all signal (Lichtenberger et al., 2008).

Whistler traces are automatically identified in the incoming data stream. The whistler detection algorithm is based on two-dimensional image correlation: dynamic spectra are computed for $14 \mathrm{~s}$ overlapping data windows and correlated with a pattern made from a model whistler. The model whistler is based on Bernard's (1973) approximation. At low-latitude stations the appearance of low dispersion whistlers is the main factor. Thus the mid-latitude algorithm with lowered dispersion $(D)$ and higher nose frequency $\left(f_{n}\right)$ can be applied (Lichtenberger et al., 2008). The practical values are $f_{n}=50-100 \mathrm{kHz}$ and $D=5-15 \mathrm{~s}^{1 / 2}$ for low latitude. However, the task here is more complicated because of the frequent appearance of midlatitude whistlers in conjunction with our low-latitude ones. The algorithm applies various techniques to remove the effects of unwanted signals including sferics, power line harmonics, and military and navigation VLF transmitters.

The AWD system has been installed and working at Varanasi, Allahabad and Lucknow since December, 2010 and has collected a lots of broad band as well as narrow band VLF data. In the present study we have analyzed the whistlers recorded at Varanasi and Allahabad only and due to poor data quality for Lucknow station we have not included it in the present analysis. The broad band data consists of variety of whistlers and tweeks. Large number of whistlers has been 
observed during routine recording of VLF data by AWD at Varanasi in the month of March 2011. Various types of whistlers have been recorded at Varanasi which is shown in Figure 1. The whistlers are marked by W1, W2, W3.....etc. and the causative lightning sferics are marked by S1, S2, S3.....etc. Figure 1a shows a typical example of single whistler trace observed at Varanasi on $19^{\text {th }}$ March 2011 at 21:58:04.4024 UT. There are doublet whistlers W1 and W2 in the Figure $1 \mathrm{~b}$ recorded at 21:07:55.6264 UT on 21 March, 2011. Figure 1c contains three whistlers observed at 20:58:34.0688 UT on $30^{\text {th }}$ March, 2011. Similarly Figure 1d shows four whistlers, Figure 1e shows five, Figure 1f shows six, Figure 1g shows seven, Figure 1h shows eight and Figure 1i shows ten whistlers observed at 21:47:12.6616 UT, 22:15:05.5976 UT, 22:18:08.0816 UT, 21:42:27.8992 UT, 21:48:25.4824 UT on 21 ${ }^{\text {st }}$ March, 2011 and at 21:17:29.64 UT on $30^{\text {th }}$ March, 2011 respectively. It is clearly observed that all the recorded whistlers are accompanying with causative lightning sferics. To find the causative lightning strikes corresponding to whistlers, lightning data from WWLLN has been used in the present study.

\section{Results and Discussions:}

\subsection{Whistlers Occurrence Statistics:}

It is observed that, in general, whistler activity at low latitude Indian stations is low and sporadic (Singh, 1993; Singh et al, 2007; Singh et al., 2012). The maximum monthly occurrence rate occurred during January to April, i.e. during the winter months (Singh et al., 2007; Srivastava et al., 2013). This is obviously due to the lightning activity in the conjugate hemisphere. After analysis we found that AWD captured 1081 whistlers at Varanasi and 1219 whistlers at Allahabad during the year 2011. In the present study, we report observations of large 
number of whistlers during the months of March, 2011 at both the Indian stations Varanasi and Allahabad. During the month of March, 2011 we recorded plenty of whistlers only on the following dates: $19^{\text {th }}$ March, 30 ${ }^{\text {th }}$ March and $31^{\text {st }}$ March, 2011 simultaneously at both stations Varanasi and Allahabad and on $21^{\text {st }}$ March, 2011 only at Varanasi. The hourly occurrence rate of whistlers recorded at Varanasi during March, 2011 is shown in Figure 2a. The hourly occurrence rate of whistlers recorded at Allahabad during March, 2011 is shown in Figure 2b. In the month of March, 2011 AWD detected 1081 whistlers at Varanasi but only 323 whistlers were detected at Allahabad. It is clearly seen from Figure 2 that Allahabad has less recording of VLF data (marked ND) due to fault in recording system. About $48 \%$ of whistlers observed at Varanasi are made of a single trace and remaining $52 \%$ are of multi-trace whistlers. All these whistlers were recorded during nighttimes and no whistler activity was found in the daytime. This may be attributed to the heavy absorption of VLF waves by the daytime D-region of ionosphere.

The occurrence of whistlers at our low latitude Indian stations compared to mid-latitudes stations is very low. The first AWD system has been working in Tihany, Hungary $(\mathrm{L}=1.8)$, and Litchtenber et al. (2008) reported that it has collected 100,000 whistler traces per year. Using AWD system operating in Dunedin, New Zealand, Rodger et al. (2009) reported the detected 92,528 individual whistler events containing 236,019 whistler traces during 530 days. Rodger et al. (2009) showed that about 58\% of the Dunedin, New Zealand observed whistlers are made of a single trace; that is, roughly $42 \%$ are multi-trace. Whereas Litchtenberger et al. (2008) showed that vast majority of the whistlers observed by the Tihany AWD are single-trace events. The conjugate point of Varanasi and Allahabad lies over the ocean and hence thunderstorm activity is relatively low as compared to that over the land (Christian et al., 2003). This may be one of the reasons for overall low whistler activity at Varanasi and Allahabad. The whole period of 
observations of whistlers at Varanasi and Allahabad presented above is geomagnetically quiet having maximum $\mathrm{Kp}=1_{+}$and Dst-index $=-13 \mathrm{nT}$.

\subsection{Whistler-Lightning Connections:}

For one-hop whistlers, one would expect the appropriate lightning source population to be that in the geomagnetic conjugate hemisphere. Initially for low latitude station Yamako (geomag. lat. $25^{\circ} \mathrm{N}$ ) Ohta and Hayakawa (1990) compared whistler activity with thunderstorm activity in the conjugate region and did not find any correlation between the two. Kumar et al. (2007) also reported similar results for whistlers observed at low latitude station Suva, Fiji (geomag. lat. $22.1^{\circ} \mathrm{S}$ ) and suggested that whistler occurrence at any station is controlled more by the propagation effects in the ionosphere and magnetosphere than by the lightning activity in the conjugate region. However, Singh et al. (2012) reported that low latitude ground whistlers are most likely linked with their causative lightning strikes located near the conjugate region using the GLD360 lightning location network. Recently, Srivastava et al. (2013) also reported one-toone relationship between low latitude whistlers and conjugate source lightning strikes using the WWLLN data. Hence, to confirm the recent findings that low latitude whistlers are correlated with the conjugate source lightning strikes, we have analyzed large number of whistlers recorded simultaneously at Varanasi and Allahabad on $30^{\text {th }}$ March, 2011 between 20 UT and 21 UT hours and corresponding lightning data from WWLLN.

The exact time of the causative sferics for the observed whistlers is computed using the

method described by Helliwell (1965) by plotting the delay time ' $t$ ' versus ' $f^{1 / 2}$ ' of the whistler frequencies ' $f$ ' and extrapolating the line to meet the origin. If the line passes through the origin, the selected sferics is the causative sferics and the corresponding time is the time of causative 
lightning stroke for the particular whistler. The dispersion ' $D$ ' of the whistler is obtained from the product of travel time of the whistler frequency components and square root of frequency components (Helliwell, 1965). A typical plot of delay time ' $t$ ' versus ' $f{ }^{1 / 2}$ ' for a whistler (shown in Figure 1a) observed on $19^{\text {th }}$ March, 2011 at 21:58:04.4024 UT is shown in Figure 3. It is clearly observed that the line passes through the origin and the selected sferics, $\mathrm{S} 1$ is the exact causative sferics for the particular whistlers W1. Hence the time of this causative sferics which is 21:58:04:3444 UT is the time of causative lightning stroke for this whistler. The reciprocal of the slope of the line gives the dispersion of the whistler, $\mathrm{D}=13.2 \mathrm{sec}^{1 / 2}$.

The lightning locations detected by WWLLN around the conjugate point of Varanasi and Allahabad between 20 UT and 21 UT hours on $30^{\text {th }}$ March, 2011 are plotted in Figure 4a. Figure $4 \mathrm{~b}$ shows the zoomed view of the conjugate area to show the conjugate points of the receiving stations with WWLLN detected lightning strikes (pink stars) and whistlers producing lightning strikes (blue circles). All of the lightning strikes originated from the region within 500-600 km radius circle from the conjugate point which supports the ducted propagation at low latitude stations. Out of 68 whistlers observed at Varanasi during one hour (between 20 UT and 21 UT) 39 whistlers were associated with coincident lightning strikes within $500 \mathrm{~km}$ from the conjugate point of Varanasi whereas at Allahabad out of 117 whistlers 63 were associated with coincident lightning strikes within $600 \mathrm{~km}$ from the conjugate point of Allahabad. Thus we observed that for both the stations more than $50 \%$ of causative sferics of whistlers were observed to match closely with the times of WWLLN detected lightning strikes within the propagation times of causative tweeks. Singh et al. (2012) observed a large number of 864 whistlers at Allahabad, in the night of 26 January 2011 and using lightning data from GLD360 geo-location network, they shown that 
$311(36 \%)$ of whistlers were associated with coincident lightnings within 200 and $450 \mathrm{~km}$ from the conjugate point of Allahabad.

Correlation study between whistler and lightning activities showed that causative lightning of whistlers were widely distributed around the conjugate point and the distance of the causative sferics from conjugate point varied from 500 to more than $2000 \mathrm{~km}$ (Weidman and Krider, 1986; Carpenter and Orville, 1989). Ondoh et al. (1979) suggested nearly overhead ionospheric exit points for whistlers observed at a Japanese station and proposed ducted propagation. Yoshino (1976) observed most of whistlers at Sugadaira, Japan, when there was thick cloud cover $\sim 500 \mathrm{~km}$ southwest of conjugate point. Collier et al. (2009) have found that whistlers observed at Tihany, Hungary, having source region of $1000 \mathrm{~km}$ surrounding conjugate point, and the source region was not circular rather displaced towards magnetic pole from conjugate point. Other studies by Collier et al. $(2010,2011)$ for whistlers observed at Dunedin and Rothera have shown opposite results that the source region is rather towards the equator from the conjugate point.

One of the advantage of low latitude whistlers while establishing correlation between whistlers and lightning activity is that the propagation delay for the sferics is much less as compared to mid- and high- latitudes (Srivastava et al., 2013). Hence, uncertainty in identifying the occurrence time of causative sferics is very small. In addition, for low latitude whistlers, the sferics associated with whistlers easily stand out in the spectrogram and there is really very little ambiguity in linking the sferics and whistlers which is not so common for mid- and highlatitudes where the propagation time is high.

The analysis of whistlers from a ground-based station has long been regarded as inexpensive and effective tools for ionosphere/plasmasphere diagnostics (Park, 1972; Sazhin et 
al., 1992; Singh et al., 1998; Carpenter, 2007). For longitudinal propagation the whistler mode dispersion relation is given as (Helliwell, 1965) $\mu^{\mu^{2}=\frac{\Pi^{2}}{\omega(\Omega-\omega)}}$ where $\mu$ is the refractive index, $\Pi$ and $\Omega$ are the plasma and electron gyrofrequency, and $\omega$ is the wave frequency. Since the refractive index depends on frequency, the whistler mode is dispersive, which is commonly characterized by the dispersion $D=t \sqrt{f}$ where $\omega=2 \pi f$ and $t$ is the time delay of the signal at frequency $f$. The dispersion and group delay are primarily dependent upon the cold plasma electron density and the Mcllwain $L$-shell (McIlwain, 1961) of the whistler duct. The computed propagation parameters of the various types of whistlers shown in Figure 1 are tabulated in Table 1. Dispersion of the observed whistlers varies between 8 and $18 \mathrm{sec}^{1 / 2}$. Previous studies have shown that the dispersion of the whistlers observed at various Indian stations range from $10 \mathrm{sec}^{1 / 2}$ to $70 \sec ^{1 / 2}$ (Siingh et al., 2008 and references therein). The dispersion analysis also shows that the observed whistlers have propagated in ducted mode and after exiting from the duct they penetrate the ionosphere and are received at Indian low latitude stations, Varanasi and Allahabad. For our low latitude Indian stations whole propagation path of whistlers lies in the ionosphere.

Various models have been used to calculate the plasmaspheric parameters (Helliwell, 1965). But no suitable model is available for low latitude whistlers whose whole path of propagation lies in ionosphere. If the path lies in the upper ionosphere $(L<1.5)$ then plasma density irregularities and plasma blobs are frequently present there; these may affect wave propagation through the processes of scattering, diffraction, reflection and non-linear interaction (Sonwalkar and Harikumar, 2000). Park (1972) gave an empirical formula to estimate the time delay due to the ionospheric path, assuming that the maximum contribution comes from the $F_{2}$ layer of the ionosphere. Using the formula 3.5 in Park (1972), the ionospheric dispersion $\mathrm{D}_{\mathrm{i}}$ is 
related with columnar electron content $\mathrm{N}_{\mathrm{i}}$ as $\mathrm{D}_{\mathrm{i}}=1.15 \times\left(\mathrm{N}_{\mathrm{i}}\right)^{1 / 2}$ where $\mathrm{N}_{\mathrm{i}}$ is in $10^{12} \mathrm{el} \mathrm{cm}^{-2}$. Since for our low latitude Indian stations all the propagation took place in the ionosphere and due to lack of any suitable model, this 'correction' can now be taken as responsible region for all time delay (dispersion). In this way, from the dispersions of the observed whistlers we can estimate the columnar electron contents along the whistler paths using the computed dispersions for all the whistlers recorded at Varanasi. We know that the whistler propagation path passes twice in ionospheric propagation, hence the columnar electron content along the complete whistler path is defined as $\mathrm{N}_{\mathrm{i}}=\mathrm{D}_{\mathrm{i}}^{2} / 5.29$. The large numbers of whistlers observed at our low latitude station Varanasi in the month of March, 2011 have been analyzed using above method. The computed propagation and ionospheric parameters of the various types of whistlers shown in Figure 1 are tabulated in Table 1. The columnar ionospheric electron contents of these observed whistlers vary between 13.21 TECU and 56.57 TECU, where $1 \mathrm{TECU}=10^{16} \mathrm{el} \mathrm{m}^{-2}$. This is in good agreement with ionospheric total electron contents (TEC) measured using Global Positioning Systems (GPS) based measurements over Indian low latitude stations (Chauhan and Singh, 2010; Kumar et al., 2012). Kumar et al. (2012) reported that TEC over low latitude Indian stations varies between 10 TECU and 50 TECU. The International Reference Ionosphere (IRI) modeled TEC over Indian stations also compares well with our computed columnar ionospheric electron contents using observed whistlers (Chauhan and Singh, 2010; Kumar et al., 2012). For better comparison of the GPS TEC, IRI TEC as well as whistlers computed TEC for particular day (times) of March 30, 2011 over Varanasi are plotted in Figure 5. The figure clearly shows that the ionospheric total electron contents derived from whistler data at Varanasi compare well with the other measurements made by other techniques. 
The analysis of whistlers recorded at a ground station yields information about the duct properties through which it has propagated. Dispersion analysis of observed whistlers (Table 1) clearly shows that there exist different ducts in the ionosphere and it is also evident that different whistlers have propagated along the geomagnetic field lines in closely spaced different ducts. Kumar et al. (2007) reported two component whistlers at Suva, Fiji and concluded that those whistlers were associated with two closely separated lightning strikes and also propagated in two close ducts. The analysis of occurrence rate and diffuseness of the whistler trace give an estimate of the lifetime and width of the duct. The lifetime of ducts may vary from a few minutes to many hours (Singh, 1993). However, statistical analysis suggests that the duct formation and decay are cyclic phenomena with the time scale of an hour (Hansen et al., 1983; Hayakawa et al., 1983; Singh and Singh, 1999). At low latitudes duct formation is difficult due to the required density enhancement ( $\sim 100 \%)$, the presence of curvature in geomagnetic field, and plasma turbulence. This may be the reason at low latitude Indian stations AWD recorded comparatively less number of whistlers in comparison to mid-latitude (Lichtenberger et al., 2008; Rodger et al, 2009).

In order the whistler waves could escape the ionosphere to the ground, their wave vector should be close to vertical because the refractive index in the neutral atmosphere is 1 , and the horizontal component of the refractive index (wave vector) should be conserved (assuming negligible horizontal electron density gradients) during the propagation. At low latitudes, this is a problem with longitudinal propagation since the magnetic field has a small inclination (it is far from being vertical). Hence observation of whistlers at low latitude is possible if there are strong horizontal gradients (e.g. edge of the equatorial ionization anomaly) in the ionosphere or presence of some irregularities like spread $\mathrm{F}$ or plasma bubbles at the time of whistler observations. Kumar and Singh (2009) using GPS based measurements showed that Varanasi is 
situated at the edge to equatorial ionization anomaly region. We have also checked our GPS scintillation data for any possibility of observation of some ionospheric irregularities or plasma bubbles and found that some weak ionospheric irregularities were present at the time of whistlers observation having scintillation index $\mathrm{S}_{4}$ varied between 0.2 and 0.3 . The rates of change of TEC during the time of observations of whistlers on March 30, 2011 varied between 5 to 9 TECU indicating the presence of plasma bubbles at the time of observations of whistlers at Varanasi. This supports the possibility of ducted propagation of whistlers at our low latitude stations Varanasi and Allahabad.

The ionospheric and other parameters derived from whistler measurements compare well with direct rocket and satellite measurements (Park et al., 1978; Singh et al., 1998; Chauhan and Singh, 2010; Kumar et al., 2012). The study of the latitudinal and longitudinal distribution of ionospheric parameters and its long term variations using rockets and satellites is financially and technically challenging, whereas these can be studied very readily by the whistler technique at a number of stations spread in latitude and longitude.

\section{Conclusion:}

Propagation features of the whistlers recorded at the low-latitude Indian stations, Varanasi and Allahabad, have been presented to identify the location of causative lightning strikes of the whistlers using WWLLN data, and to compute various propagation and plasmaspheric parameters. There were significant lightning strikes detected by WWLLN in the conjugate region around the time of occurrence of whistlers, suggesting whistler occurrence is strongly controlled by lightning activity. We observed that for both the stations more than $50 \%$ of causative sferics of whistlers were observed to match closely with the times of WWLLN detected lightning strikes 
within the propagation times of causative tweeks. All of these lightning strikes originated from the region within 500-600 km radius circle from the conjugate point of Varanasi and Allahabad which supports the ducted propagation at low latitude stations. The large numbers of whistlers observed at our low latitude station Varanasi in the month of March, 2011 have been analyzed using Bernard's method. Dispersion of the observed whistlers varies between 8 and $18 \sec ^{1 / 2}$. The dispersion analysis shows that the observed whistlers have propagated in ducted mode and after exiting from the duct they penetrate the ionosphere and are received at Indian low latitude stations, Varanasi and Allahabad. The columnar ionospheric electron contents of these observed whistlers vary between 13.21 TECU and 56.57 TECU. The ionospheric parameters derived from whistler data at Varanasi compare well with the other measurements made by other techniques.

Acknowledgements: The work is financially supported by ISRO, Bangalore, under ISROCAWSES India Phase-II program. We are thankful to both the reviewers for providing valuable comments/suggestions to improve the quality of the manuscript.

\section{References:}

Al'pert, Y. L., 1980. 40 years of whistlers. Journal of Atmospheric and Terrestrial Physics 42, 120, doi:10.1016/0021-9169(80)90117-8.

Bernard, L.C., 1973. A new nose extension method for whistlers. Journal of Atmospheric and Terrestrial Physics 35, 871-880.

Carpenter, D.L., 2007. Chung Park pioneer of magnetosphere-ionosphere coupling research. Journal of Atmospheric and Solar-Terrestrial Physics 69, 351-361. 
Carpenter, D. L., and Orville, R. E., 1989. The excitation of active whistler mode signal paths in the magnetosphere by lightning: Two case studies. Journal of Geophysical Research 94(A7), $8886-8894$.

Carpenter, D. L., Stone, K., Siren, J. C. and Crystal T. L., 1972. Magnetospheric electric field deduced from drifting whistler paths. Journal of Geophysical Research 77, 2819.

Chauhan, V., and Singh, O.P., 2010. A morphological study of GPS-TEC data at Agra and their comparison with the IRI model. Adv. Space Res 46, 280-290.

Christian, H. J., Blakeslee, R. J., Boccippio, D. J., Boeck, W. L., Buechler, D. E., Driscoll, K. T., Goodman, S. J., Hall, J. M., Koshak, W. J., Mach, D. M. and Stewart, M. F., 2003. Global frequency and distribution of lightning as observed from space by the Optical Transient Detector. Journal of Geophysical Research 108(D1), 4005, doi:10.1029/ 2002JD002347.

Chum, J., Jiricek, F., Santolik, O., Parrot, M., Diendorfer, G., and Fiser J., 2006. Assigning the causative lightning to the whistlers observed on satellites. Annales Geophysicae 24(11), $2921-2929$.

Collier, A. B., Hughes, A. R.W., Lichtenberger, J., and Steinbach, P., 2006. Seasonal and diurnal variation of lightning activity over southern Africa and correlation with European whistler observations. Annales Geophysicae 24(2), 529-542.

Collier, A. B., Delport, B., Hughes, A. R. W., Lichtenberger, J., Steinbach, P., Öster, J., and Rodger, C. J., 2009. Correlation between global lightning and whistlers observed at Tihany, Hungary. Journal of Geophysical Research 114, A07210, doi:10.1029/2008JA013863.

Collier, A. B., Bremner, S., Lichtenberger, J., Downs, J. R., Rodger, C. J., Steinbach, P., and McDowell, G., 2010. Global lightning distribution and whistlers observed at Dunedin, New Zealand. Annales Geophysicae 28(2), 499-513, doi:10.5194/angeo-28-499-2010. 
Collier, A. B., Lichtenberger, J., Clilverd, M. A., Rodger, C. J., and Steinbach, P., 2011. Source region for whistlers detected at Rothera, Antarctica. Journal of Geophysical Research 116, A03219, doi:10.1029/2010JA016197.

Hansen, H.J., Scourfield, M.W.J. and Rash, J.P.S., 1983. Whistler duct lifetimes. Journal of Atmospheric and Terrestrial Physics 45, 789-794.

Hayakawa, M., and Tanaka, Y., 1978. On the propagation of low latitude whistlers. Review of Geophysics and Space Physics 16, 111-123.

Hayakawa, M., Tanaka, Y., Okada, T. and Ohtsu, J., 1983. Time scales for the formation, life time and decay of low latitude whistler ducts. Annales Geophysicae 1, 515-518.

Helliwell, R.A., 1965. Whistlers and Related Ionospheric Phenomena. Stanford University Press, Stanford.

Inan, U.S., Cummer, S.A., Marshall, R.A., 2010. A survey of ELF and VLF research on lightning-ionosphere interactions and causative discharges. Journal of Geophysical Research 115, A00E36, doi:10.1029/2009JA014775.

Kumar S. and Singh A. K., 2009. Variation of ionospheric total electron content in Indian low latitude region of the equatorial anomaly during May, 2007 - April, 2008. Advances in Space Research 43, 1555-1562.

Kumar, S., Priyadarshi, S., Krishna, Gopi., Singh, A. K., 2012. GPS-TEC variations during low solar activity period (2007-2009) at Indian low latitude stations. Astrophys Space Sci $339,165-178$.

Kumar, S., Anil, D., Kishor, A. and Ramachandran, V., 2007. Whistler observed at low latitude ground based VLF facility at Fiji. Journal of Atmospheric and Solar-Terrestrial Physics 69, 1366-1376. 
Lichtenberger, J., Hamar, D., Ferencz, Cs., Ferencz, O.E., Collier, A. and Hughes, A., 2005. What are the sources of whistlers? URSI XVIII, Gen. Ass., H.2, New Delhi, India.

Lichtenberger, J., Ferencz, C., Bodnár, L., Hamar, D., Steinbach, P., 2008. Automatic Whistler Detector and Analyzer system: Automatic Whistler Detector. Journal of Geophysical Research 113, A12201, doi:10.1029/2008JA013467.

Mcllwain, C. E., 1961. Coordinates for mapping the distribution of magnetically trapped particles. Journal of Geophysical Research 66, 3681-3691, doi:10.1029/JZ066i011p03681.

Morgan, M.G., 1980. Some features of proresonance (PR) whistlers. Journal of Geophysical Research 85, 103-106.

Ohta, K., and Hayakawa, M., 1990. The correlation of whistler occurrence rate at a low latitude with thunderstorm activity at its conjugate region and with solar activity. Pure and Applied Geophysics 133(1), 167-178, doi:10.1007/BF00876709.

Ondoh, T., Kotaki, M., Murakami, T., Watanabe, S., and Nakamura, Y., 1979. Propagation characteristics of low latitude whistlers. Journal of Geophysical Research 84, 2079-2104, doi:10.1029/JA084iA05p02097.

Park, C. G., 1972. Methods to determine electron concentrations in the magnetosphere from nose whistlers. Tech. Rep. 3454-1, Radio Science Laboratory, Stanford Electr. Lab., Stanford University, Stanford, California.

Park, C.G., Carpenter, D.L. and Wiggin, D.B., 1978. Electron density in the plasmasphere: whistler data on solar cycle, annual, and diurnal variations. Journal of Geophysical Research $83,3137-3144$. 
Rodger, C. J., Lichtenberger, J., McDowell, G., and Thomson, N. R., 2009. Automatic whistler detection: Operational results from New Zealand. Radio Science 44, RS2004, doi:10.1029/2008RS003957.

Sazhin, S.S., Smith, A.J. and Sazhin, E.M., 1990. Can magnetospheric electron temperature be inferred from whistler dispersion measurements? Annales Geophysicae 8, 273-285.

Sazhin, S.S., Hayakawa, M., Bullough, K., 1992. Whistler diagnostics of magnetospheric parameters: A review. Annals Geophysicae 10(5), 293-308.

Siingh, D. Singh, A.K., Patel, R.P., Singh, R., Singh, R.P., Veenadhari, B., and Mukherjee, M., 2008. Thunderstorms, lightning, sprites and magnetospheric whistler-mode radio waves. Surveys in Geophysics 29, 499-551, DOI 10.1007/s10712-008-9053-z, 2008.

Singh, R.P., 1993. Whistler studies at low latitudes: a review. Indian Journal of Radio and Space Physics 22, 139-155.

Singh, B. and Tantry, B.A.P., 1973. On ducting of whistlers of low latitudes. Annales Geophysicae 29, 561-568.

Singh, A. K. and Singh, R.P., 1999, Duct life times at mid latitudes. Periodica Polytechnica Ser. El. Eng., 43, 43-52.

Singh, R.P., Singh, A.K., and Singh, D.K., 1998. Plasmaspheric parameters as determined from whistler spectrogram: a review. Journal of Atmospheric and Solar-Terrestrial Physics 60, $495-508$.

Singh, R.P., Singh, R., Lalmani, Hamer, D., and Lichterberger, J., 2004. Application of matched filtering to short whistlers recorded at low latitudes. Journal of Atmospheric and SolarTerrestrial Physics 66, 407-413.

Singh, S., Patel, R.P., Singh, K.K., Singh, A.K. and Singh, R.P., 2007. Role of geomagnetic 
disturbances on VLF whistler wave activity at low latitudes. Planetary and Space Science 55, 1218-1224, doi.10.1016/pss-2007.02.001.

Singh, A. K., Singh, K. K., Singh, S. B., Singh, A. K., and Lalmani, 2011. Multiflash whistlers in ELF-band observed at low latitude. Annales Geophysicae 29, 91-96.

Singh R., Cohen, M. B., Maurya, A. K., Veenadhari, B., Kumar, S., Pant, P., Said, R. K., Inan, U. S., 2012. Very low latitude ( $(=1.08)$ whistlers. Geophysical Research Letter 39, L23102. http://dx.doi.org/10.1029/2012GL054122.

Smith, R.L. and Angerami, J.J., 1968. Magnetospheric properties deduced from OGO-1 observations of ducted and nonducted whistlers. Journal of Geophysical Research 73, 1-20.

Sonwalker, V.S. and Harikumar, J., 2000. An explanation of ground observations of auroral hiss: role of density depletion and meter-scale irregularities. Journal of Geophysical Research 105, $18867-18883$.

Srivastava, P. R., Gokani, S. A., Maurya, A. K., Singh, R., Kumar, S., Veenadhari, B., Selvakumaran, R., Singh, A. K., Lichtenberger, J., 2013. One-to-one relationship between low latitude whistlers and conjugate source lightning discharges and their propagation characteristics. Advances in Space Research 52, 1966-1973.

Storey, L.R.O., 1953. An investigation of whistling atmospherics. Philosophical Transaction of Royal Society (London) 246A, 113-141.

Tarcsai, G., Szemeredy, P., and Hegymegi, L., 1988. Average electron density profiles in the plasmasphere between $\mathrm{L}=1.4$ and 3.2 deduced from whistlers. Journal of Atmospheric and Terrestrial Physics 50, 607-611, doi:10.1016/0021-9169(88)90058-X.

Walker, A.D.M., 1976. The theory of whistler propagation. Review of Geophysics and Space Physics 14, 629-638. 
Weidman, C. D. and Krider, E. P., 1986. The amplitude spectra of lightning radiation fields in the interval from 1 to $20 \mathrm{MHz}$. Radio Science 21, 964-970, doi:10.1029/RS021i006p00964.

Xu, J. S., Tian, M., Tang, C. C., Hayakawa, M., Ohta, K. and Shimakura, S., 1989. Direction finding of night-time whistlers at very low latitudes in China: Preliminary results. Planetary and Space Sciences 37, 1047-1052, doi:10.1016/0032-0633(89)90077-9.

Yoshino, T., 1976. Low-latitude whistlers and cloud distributions in the conjugate area. Journal of Geophysical Research 81(A25), 4793-4796.

\section{Caption to Figures}

Figure 1: Various types of whistlers observed at Varanasi during the month of March, 2011. The whistlers are marked by W1, W2, W3....etc. and the corresponding causative lightning sferics are marked by S1, S2, S3 ....etc.

Figure 2: The hourly occurrence rate of whistlers recorded at (a) Varanasi and (b) Allahabad during March, 2011 (ND=No data).

Figure 3: A typical plot of delay time ' $t$ ' versus ' $f^{1 / 2}$ ' for a whistler (shown in Figure 1a) recorded at Varanasi on $19^{\text {th }}$ March, 2011 at 21:58:04.4024 UT. The inverse of the slope of the line gives the dispersion.

Figure 4: (a) Location of receiving stations Varanasi and Allahabad along with the lightning locations detected by WWLLN around the conjugate point of Varanasi and Allahabad between 20 UT and 21 UT hours on $30^{\text {th }}$ March, 2011. (b) Zoomed view of the 
conjugate area to show the conjugate points of the receiving stations with WWLLN detected lightning strikes (pink stars) and whistlers producing lightning strikes (blue circles).

Figure 5: Variation of GPS TEC, IRI TEC as well as whistlers computed TEC for March 30, 2011 over Varanasi. 